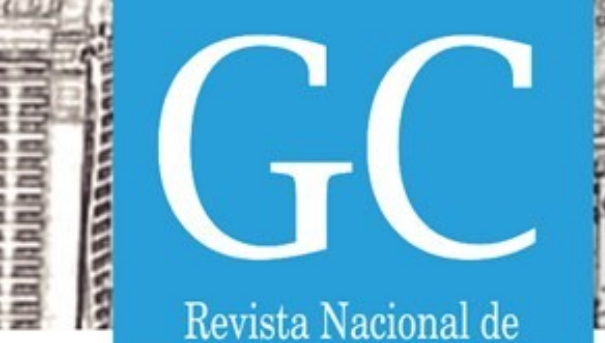

Revista Nacional de

Gerenciamento de Cidades National Journal of Cities Management

\title{
Espaços comerciais no térreo de um corredor urbano
}

Commercial spaces on the ground floor of an urban corridor

Locales comerciales en la planta baja de un corredor urbano

\section{Adilson Costa Macedo}

Arquiteto, Professor Doutor

Universidade São Judas Tadeu, USJT

Lider do Grupo de Pesquisa Arquitetura da Cidade GPAC/USJT

ac.macedo@terra.com.br

\section{Jessica Lorelay Cuscan Guidoti}

Arquiteta, Mestranda

Universidade São Judas Tadeu, USJT

Pesquisadora, GPAC/USJT 




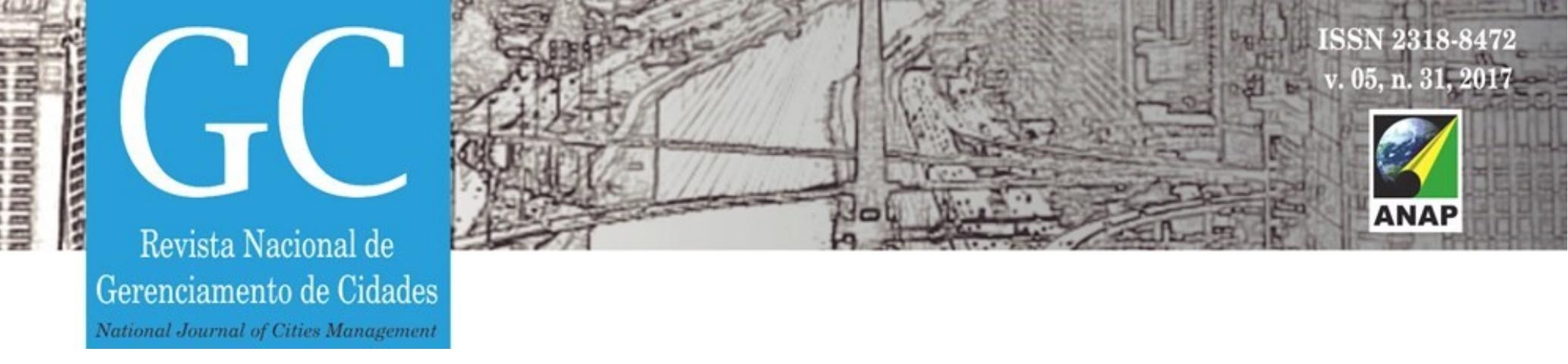

\section{O CORREDOR PAULISTA E SEU ASSENTAMENTO NO SÍTIO}

O corredor assente no espigão, divisor de águas entre os rios Tietê e Pinheiros, atravessa a cidade de Oeste a Sul e tem comprimento de $13 \mathrm{~km}$. O trecho da Avenida Paulista, presente objeto de estudo tem $2,7 \mathrm{~km}$, sendo equivalente a vinte por cento do total do corredor. A altitude do Corredor Paulista varia de oitocentos metros no extremo oeste até setecentos e noventa ao Sul, marcando os pontos altos do centro expandido da cidade (espaço entre os dois rios). Devido às cotas elevadas do espigão, foram instaladas diversas torres de transmissão nas coberturas dos prédios e em algumas delas foram construídos helipontos. As torres, mais o vai e vem de helicópteros, conferem uma imagem inusitada ao panorama (skyline) desta parte da cidade. Figura 2

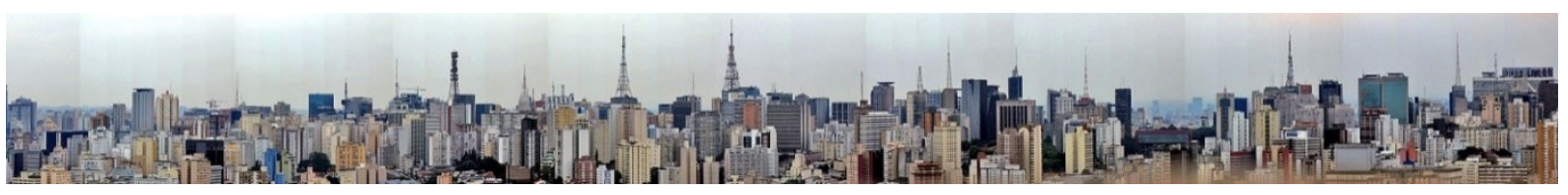

Figura 2. Avenida Paulista, vista desde o Edifício Itália (45 pavimentos). Fonte: Commons Wikimedia 05.03.2017

A Avenida Paulista desde o início do século XX tem passado por constantes transformações. De uma avenida aberta atravessando área rural, ainda no final do século XIX até hoje ela sofreu um desenvolvimento que é peculiar aos das áreas que passam do rural para o urbano: as fazendas são subdivididas em chácaras e estas são fragmentadas lotes. $O$ fracionamento depende da percepção de mercado que possui o empreendedor. No caso da Paulista, o entendimento da sociedade no início do século XX foi de que a posição em cota alta, proeminente na cidade, poderia ser o local para os palacetes daqueles feitos milionários pela produção cafeeira. Assim a faixa lindeira defronte para a Avenida, foi parcelada em lotes grandes, balizados pelo sistema reticular das quadras, resultantes de vias ortogonais traçadas com espaçamento de cem a duzentos metros. Atendendo muito bem a burguesia do tempo do café,que foi a mola propulsora da economia de São Paulo (e do Brasil).Desde meados do século XX os lotes grandes das casas passaram a dar lugar a construção de edifícios;não só os da Avenida Paulista.Um conglomerado de edifícios altos, com exceção ao loteamento dos bairrosjardim, passaria a caracterizar a paisagem urbana do centro expandido da cidade de São Paulo (TOLEDO, 1983). Figura 3. 

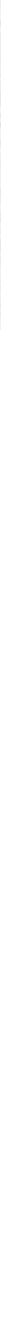

Figura 3 A: 1891, B: 1906, C: 1957, D: 2017. Fonte: Aquarela J. Martin, domínio público, arquivo Eletropaulo, autores

O relevo tipo espigão - divisor de águas - se identifica por apresentar declividade para ambos os lados, em geral com desníveis mais acentuados para o lado Norte e mais amenos pelo lado Sul. Característica exemplificada pelas quatro quadras que estão no entroncamento da Avenida Paulista com a Rua Augusta. Basta observar a implantação do Conjunto Nacional (quadra inteira) e atravessando a Avenida, os vizinhos Banco Safra e o Conjunto Center 3. As primeiras quadras acompanham de cada lado a Avenida, onde os lotes das faixas lindeiras mais a caixa da rua compõe o corredor. Os lotes voltados para as vias paralelas a Paulista, marcam o traçado do sistema das vias auxiliares da Avenida. Os desníveis da área chegam até doze metros (Figura 4).

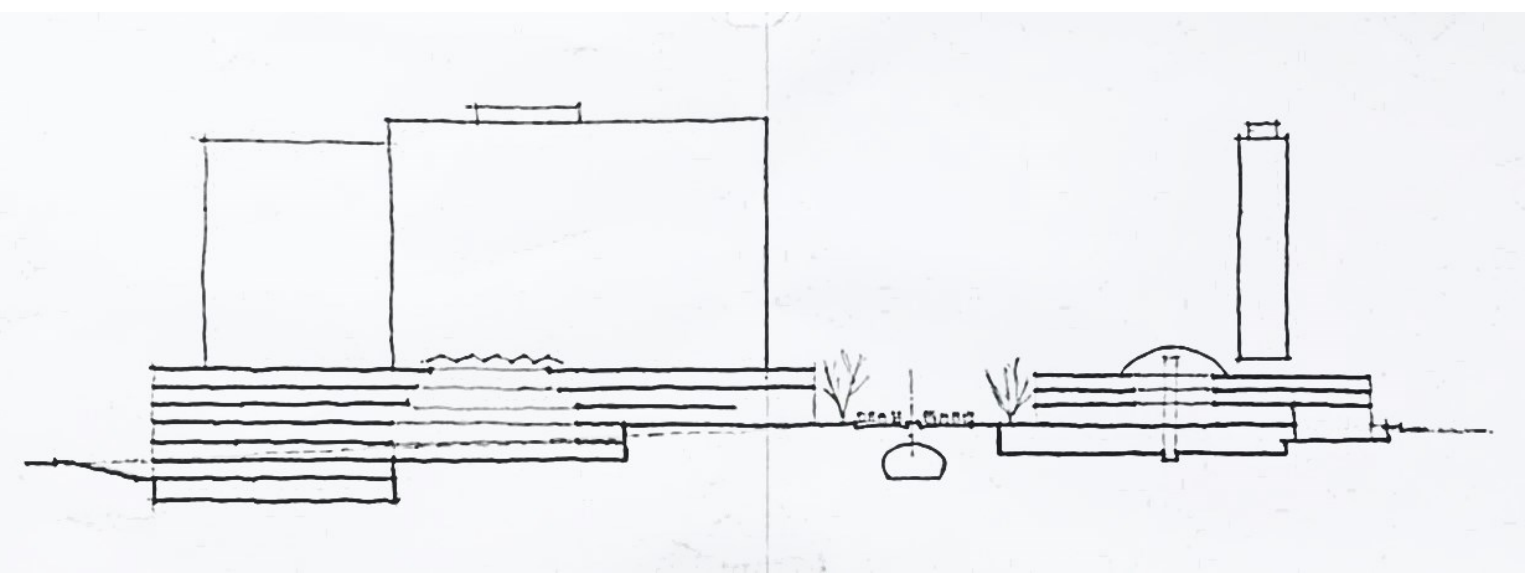

Figura 4: Corte abrangendo o Conjunto Nacional e o Shopping Center 3. Fonte: Autores. 

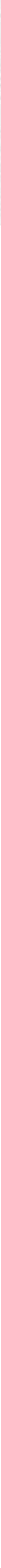

Figura 5: Avenida Paulista. Fonte: Autores / Google Earth Pro 02.03.2017

Compreende-se a Avenida Paulista como um espaço aberto na última década do século XIX e que hoje virou um lugar, espaço apropriado pelas pessoas, onde se reside, se trabalha e se convive. Onde a rua é usada para recreação todos os finais de semana e de vez em quando acontecem grandes eventos (protestos, carnaval, parada gay...). A Avenida tem um significado especial para os moradores da 


\section{A CARACTERIZAÇÃO DOS TIPOS}

O tipo predominante de espaços nos térreos dos imóveis localizados no Corredor Paulista destina-se principalmente a abrigar atividades de comércio e serviços, mesmo quando nos pavimentos superiores ocorra uso residencial. São raros os casos de o imóvel inteiro ser ocupado por unidades residências. Na Paulista existem vários prédios do tipo corporativo, onde uma empresa ocupa o imóvel inteiro, ficando o térreo como um pavimento de recepção e controle do acesso para o interior do edifício. Diferenciam-se os prédios administrativos das instituições bancárias, onde o térreo é ocupado por uma agencia de atendimento público. Neste caso, apesar do relativo controle do acesso se considerou a agencia como uma loja, tendo sido assim mapeada para efeito de análise.

Existem os prédios que não se enquadram nos tipos relacionados acima, onde é intenso o cotidiano de vai e vem das pessoas; são os prédios de caráter único como o museu, a escola, a igreja e bens tombados (Rossi, 1977). Na Paulista, estes prédios de caráter único são complementos do conjunto dos edifícios altos e promovem a diversidade da paisagem urbana. Não só pela diferenciação da volumetria, como pelos dias e as horas em que o fluxo de pessoas é maior, momentos em que são visitados. Eles sugerem uma classificação própria de tipos, que não será estudada no momento.

Quanto ao acesso livre do térreo foram determinadas situações tipo, em função da relação do imóvel com a quadra e o corredor. Para alguns tipos, significativos pela permeabilidade (passagem livre de pessoas através do térreo) se apresentam ilustrações por fotografia acentuando as relações dos acessos ao lote e ao edifício. Descreve-se no manuscrito apenas os tipos que são característicos de situação perceptível em um primeiro apanhado geral, admitindo-se que talvez ajam tipos para serem adicionados ou variantes de determinado tipo para ser considerada.

Tipo 1 - Edifício situado em terreno de meio de quadra, com a frente voltada para o corredor.

É o caso mais frequente, onde a porta da frente está voltada para a avenida e o embasamento (térreo e sobreloja), recuado na frente encosta nas divisas laterais do lote. $O$ hall de elevadores volta-se para a rua. Pode haver lojas voltadas diretamente para a rua. Voltadas para rua como linguagem corrente, neste manuscrito será usada para substituir: voltadas para a Avenida Paulista. Figura 8

Caso da galeria com entrada e saída pela mesma galeria interna. Por ela se faz o acesso ao hall de elevadores. Este tipo possibilita haver vitrines e o acesso direto para as lojas que tem contato direto com a calçada. Nesta frente para a Avenida acontece também o acesso de veículos à garagem. 


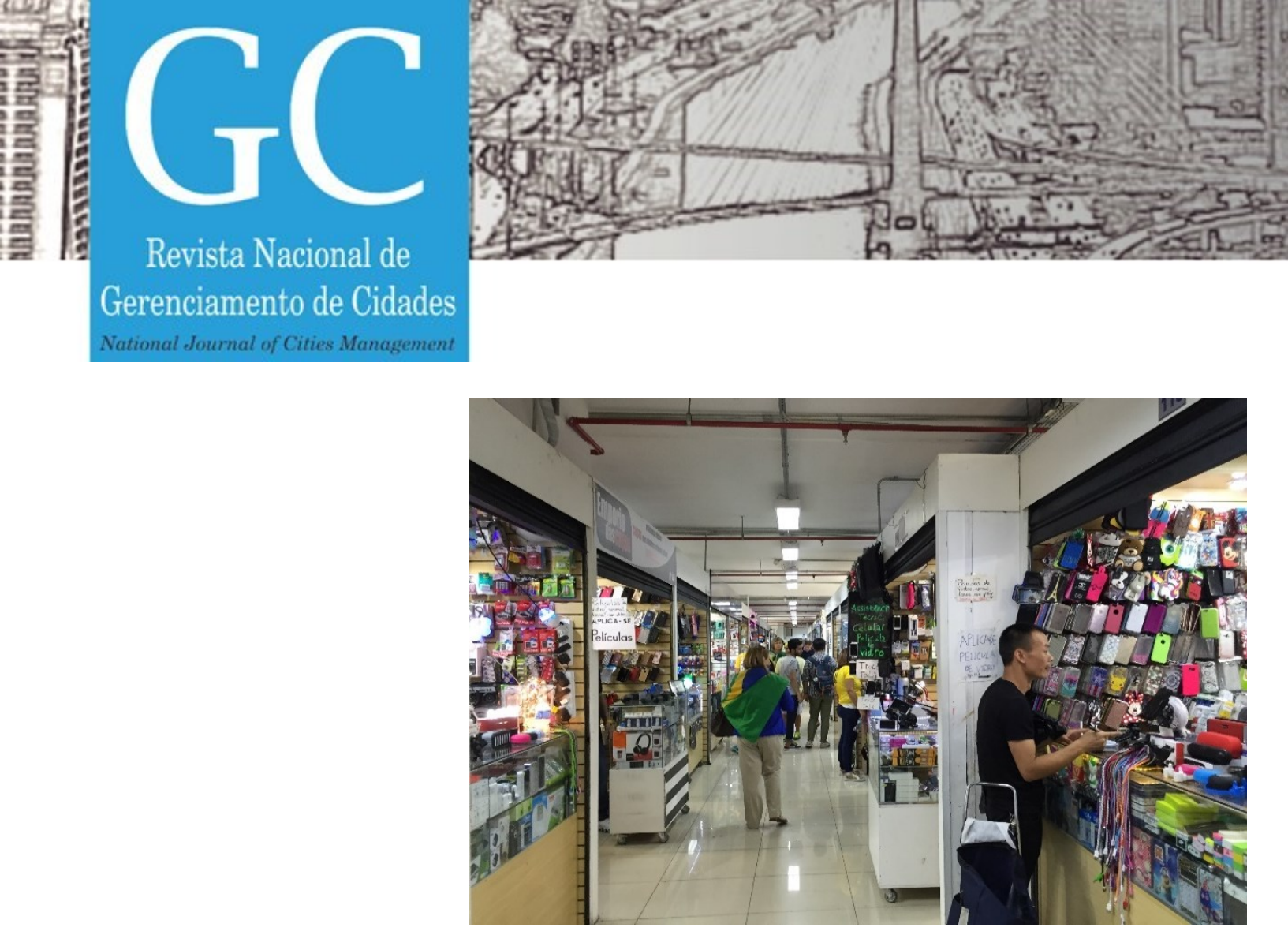

Figura 9: Galeria comercial, pequenas lojas. Fonte: Autores

Tipo 2 - Lote de meio de quadra, entre duas ruas paralelas, com galeria ligando as ruas.
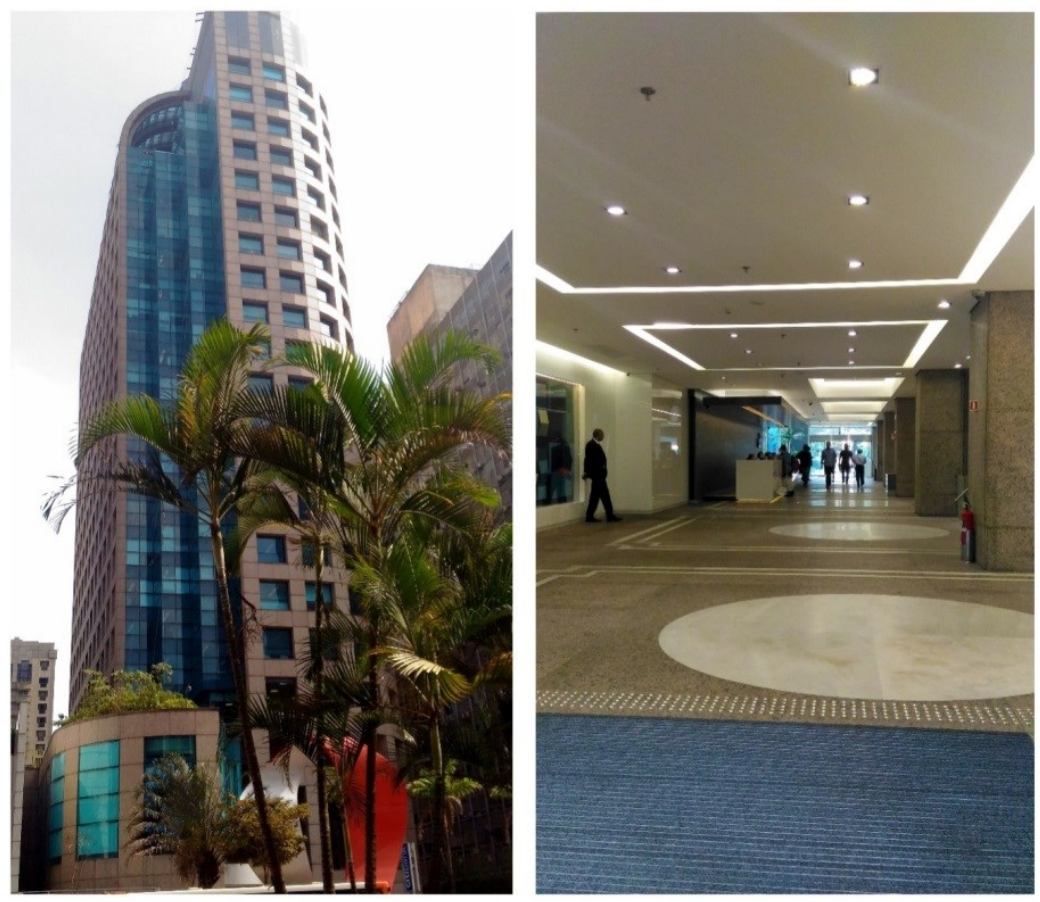

Figura 10: Galeria interligando ruas paralelas. Fonte: Autores

Tipo 3 - Terreno de esquina, galeria com acesso por duas ruas perpendiculares 

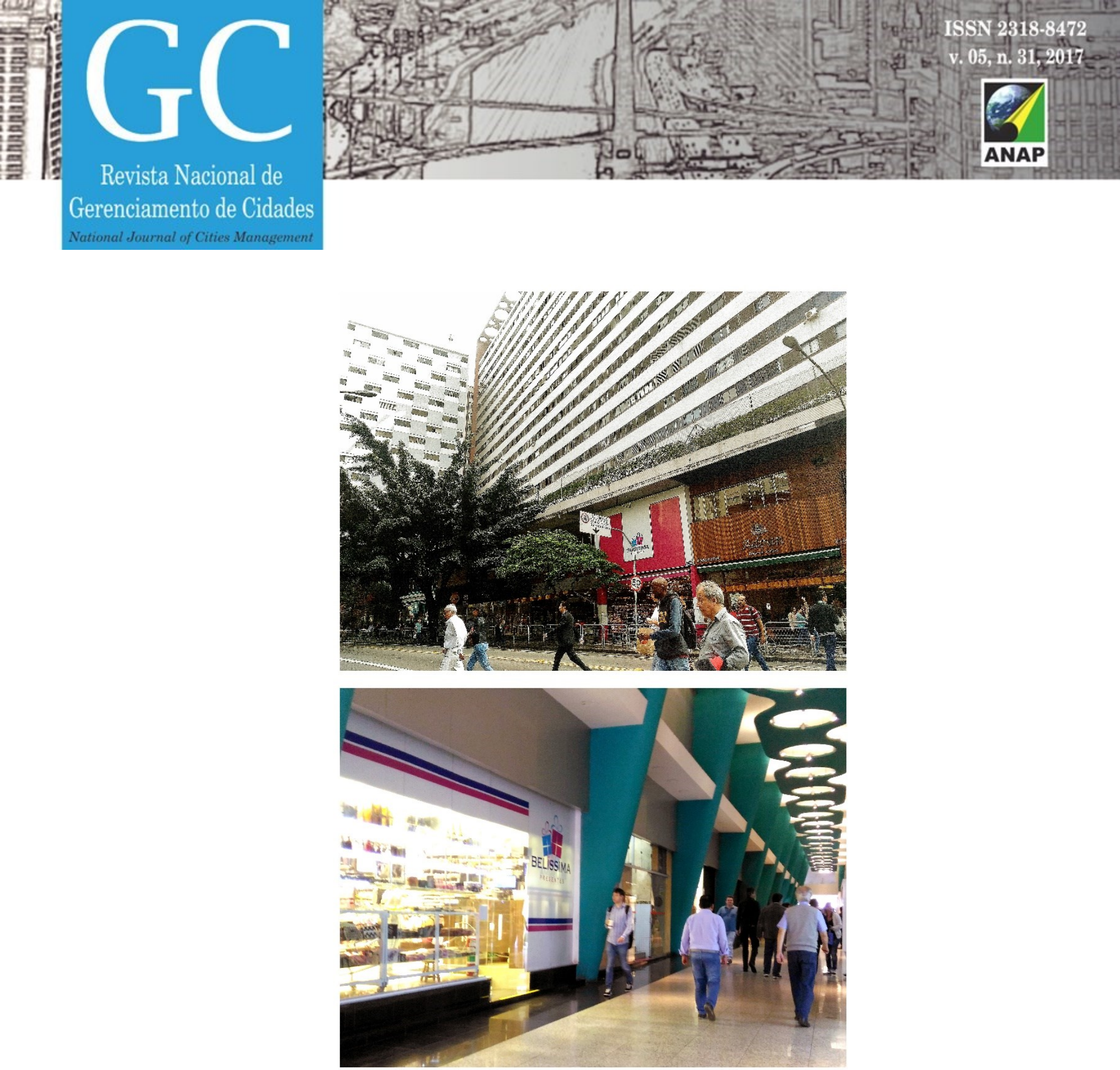

Figura 12: Galeria com acesso por três ruas. Fonte: Autores

Tipo 5 - Terreno largo de esquina, acesso por três ruas, espaço interior do tipo shopping center, tendo uma ou mais torres localizadas sobre os pavimentos comerciais.

Neste tipo de situação a largura do terreno favorece a implantação de centro comercial no térreo com as sobrelojas que se julgar conveniente em pavimentos acima. Sobreposto ao conjunto podem aparecer uma ou mais torres. No exemplo existem duas torres 

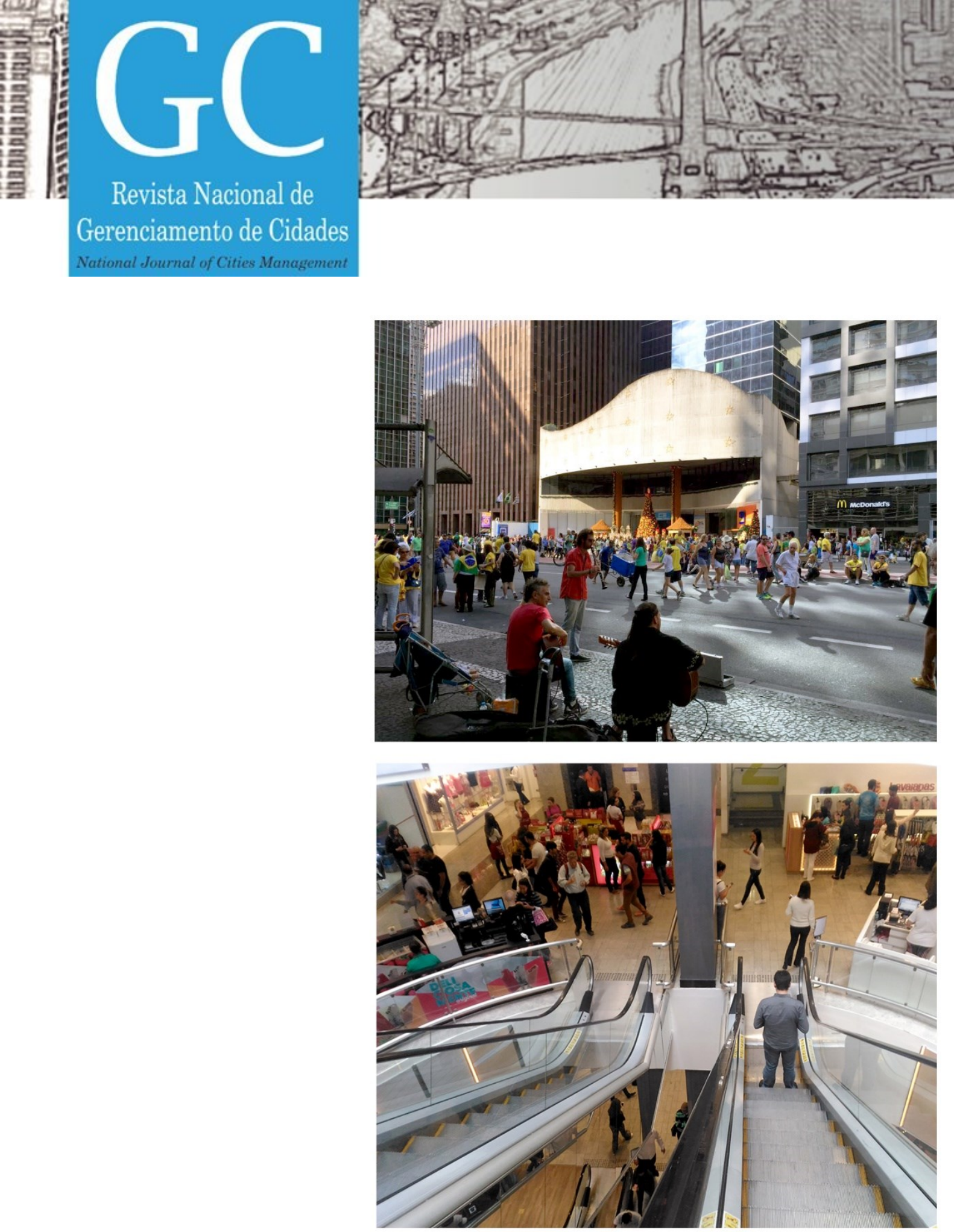

Figura 13: Lote voltado para três ruas, área central tipo shopping center. Fonte: Autores.

Tipo 6 - Terreno largo de esquina, acesso por três ruas, espaço interior tipo shopping center, com uma única torre localizada sobre os pavimentos comerciais.

Os exemplos representativos dos tipos 5 e 6, figuras 13 e 14, são edificações em lotes situados do mesmo lado da Avenida Paulista, sendo favorecidos pelo declive do terreno para a implantação da garagem, com entrada pela rua de fundo. Isto organiza a chegada dos serviços e a entrada de estacionamento dos clientes. 


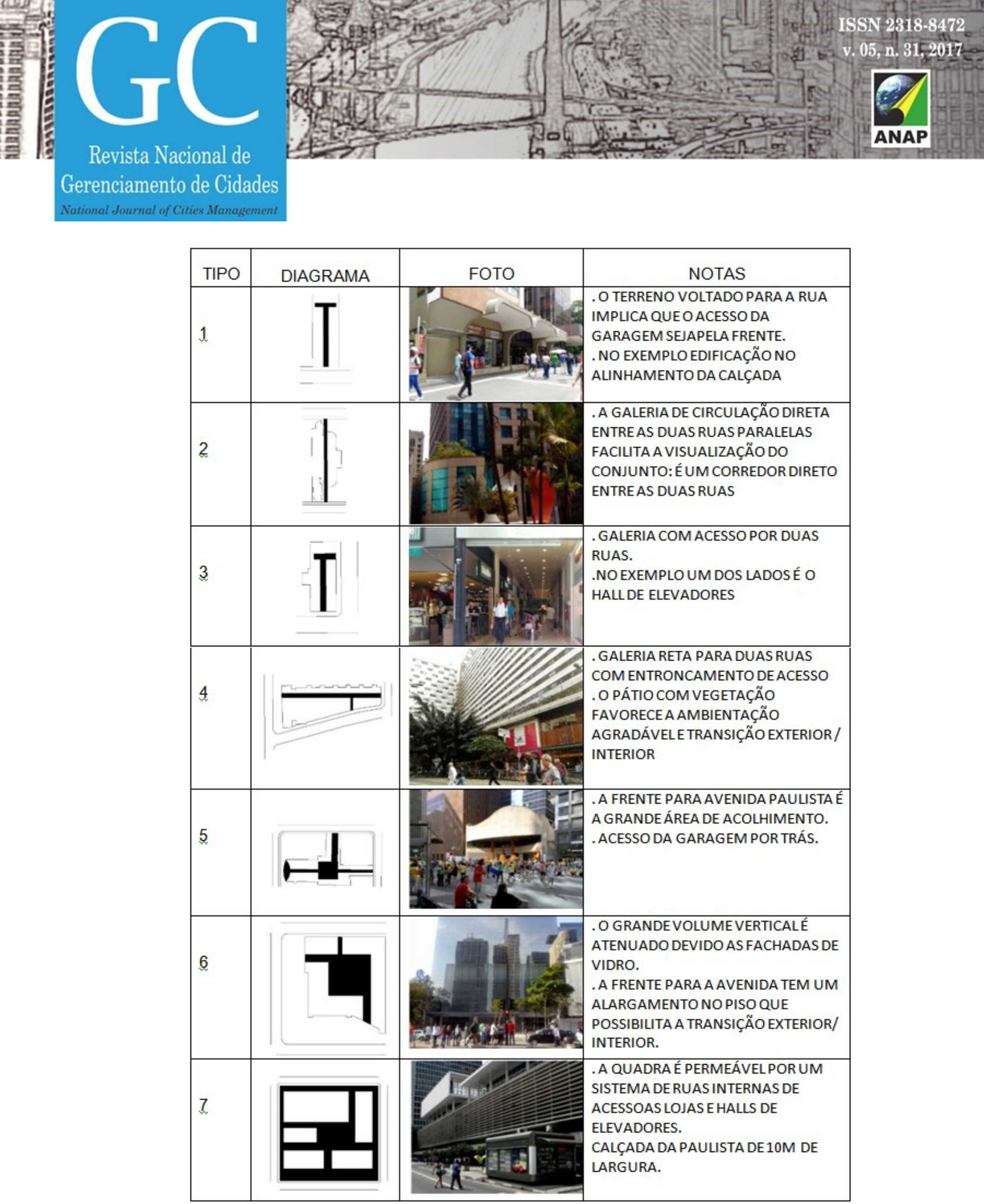

Figura 16: Quadro resumo dos tipos. Fonte: Autores 


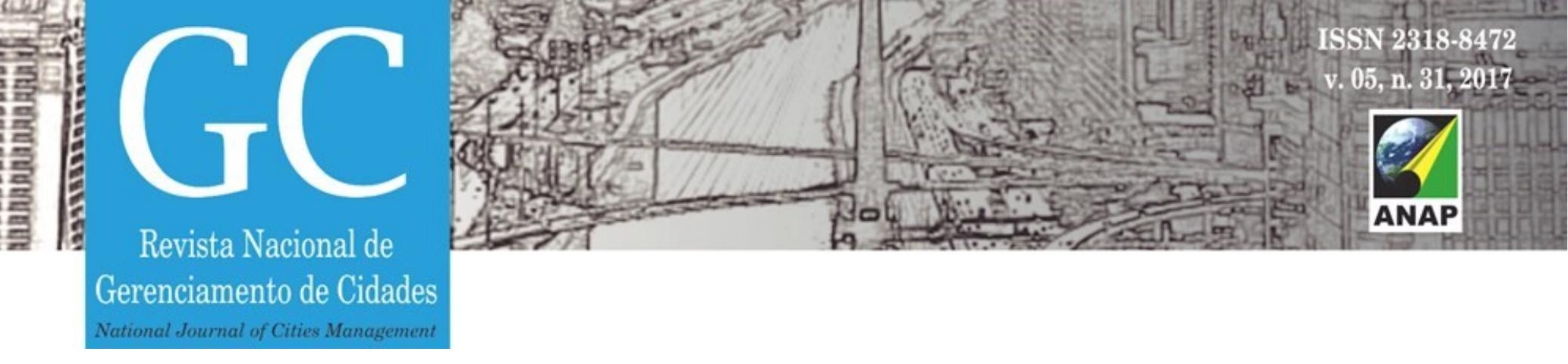

\section{CONSIDERAÇÕES FINAIS}

Mostrou-se o resultado parcial da pesquisa que vem sendo realizada pelo GPAC/USJT sobre elementos urbanos, na medida em o manuscrito trata do desenho da forma, segundo preceitos da Morfologia Urbana. Desde a geografia da área maior até o sítio de análise; passando pelo estudo da rua, quadra, lote e edifício faz-se o retrospecto da busca do desenho da forma que melhor venha atender à vontade expressa pela sociedade (Costa,2016). Ficando para outro momento, para os profissionais voltados para o estudo do uso social do espaço, precisos em especialidades tão importantes, para se integrar e formar, junto com aspectos técnicos do ambiente construído um pacote de sustentabilidade. Afinal, o desejo de todos é que a pesquisa acadêmica tenha reflexo no trabalho de profissionais da área de desenvolvimento urbano.

\section{REFERÊNCIAS}

Appleyard, D. Livable Streets. Berkeley: University of California Press.1981.

Costa, S.A.P; Gimmler Neto, M.M. Introdução a Morfologia Urbana, Belo Horizonte, Editora C/Arte. 2016.

Imbronito, M.I., Macedo, A. C., Tipos de corredores e ruas locais do Distrito da Mooca, São Paulo. In Revista de Morfologia Urbana, Universidade do Porto, Portugal, 2016.

Imbronito, M.I, Macedo, A. C, Sales, G. S. Patchwork of industrial districts around São Paulo core area. In Anais do SBE2016, Brazil- Portugal: Sustainable urban communities towards a nearly zero impact built environment. Universidade Federal do Espirito Santo, ES, 2016.

Macedo, A. O espaço urbano por partes. São Paulo. In Revista Sinopses n³8, outubro 2002, FAAUUSP,2002.

Rossi, A. Arquitectura da cidade. Lisboa; Edições Cosmos. 1977.

Speck, J. Walkable city: how downtown can save America, one step at a time. New York: Farrar, Straus \& Giroux Editors. 2012.

Toledo, Benedito Lima de. São Paulo: três cidades em um século. 2.ed. São Paulo, SP: Duas Cidades, 1983. 